\title{
Administração da morte: $A$ aposentadoria de Senhor Bougran, de J.-K. Huysmans e A Morte de Ivan Ilitch, de Lev Tolstoi
}

\author{
Administrating death in J.-K. Huysmans's Mr. Bougran's Retirement and \\ Leo Tolstoi's The Death of Ivan Ilitch
}

\author{
RÉGIS MIKAIL ABUD FILHO (1) \\ Université Paris-Sorbonne (Paris-IV).
}

\begin{abstract}
Resumo: $O$ presente artigo compara duas narrativas - $A$ aposentadoria de Senhor Bougran, de J.-K. Huysmans e A morte de Ivan Ilitch, de Lev Tostoi - partindo de uma análise do funcionalismo público e da noção de labor na literatura. Busca-se mostrar de que maneira o anúncio da morte afeta as protagonistas a partir de certos lutos e frustrações em suas vidas. De que maneira o discurso literário confrontase com o discurso administrativo e a vida no serviço público se manifesta nessas situações? São analisadas aqui topoi frequentes no realismo e no naturalismo, presente nas obras em questão, como a vegetação, a decoração e o retrato da vida comum do servidor no serviço público. Como são representadas essas existências comuns? De que maneira suas existências comuns se acomodam no espaço do discurso literário?
\end{abstract}

Palavras-chave: Labor; Morte; Luto; Absurdo, Huysmans; Tolstoi.

\begin{abstract}
This article compares two short novels - J.-K. Huysmans's Mr. Bougran's Retirement and Leo Tolstoi's The Death of Ivan Ilitch - in an analysis of public service and the concept of labor in literature. We intend to present the way through which the announcement of death affects the main characters from their grief and frustrations in their lives. How does the literary discourse oppose to the administrative discourse? How is life in public service manifested in these situations? Frequent topoi in Realism and Naturalism, present in both texts are analysed, such as vegetation, decor and a portrait of the common public worker's life. In what sense are these ordinary existences related to the idea of absurd and how do they fit in the literary discourse?
\end{abstract}

Keywords: Labour; Death; Grief; Absurd; Huysmans; Tolstoi. 
Pas ce soir, mon cher ami, je suis en course. Il pluviote (sic) et mon âme pue ${ }^{1}$.

J.-K. HUYSMANS

Imagine minha surpresa, ou melhor, minha perplexidade quando, sem deixar sua mesa e numa voz firme e curiosamente tranquila Bartleby respondeu, "Preferiria não" 2 .

HERMAN MELVILLE

Nada de propriamente trágico, se por "trágico" considerarmos a herança dramatúrgica Antiguidade e sua dimensão grandiosa, em A Morte de Ivan Ilich (1886), de Lev Tolstoi e $A$ aposentadoria de Senhor Bougran (1888), de Joris-Karl Huysmans ${ }^{3}$. Nelas, as protagonistas, homens comuns, criam-se artifícios perante a iminência de sua morte. Desprovidos do heroísmo das protagonistas virtuosas e admiráveis da literatura clássica, a percepção de suas existências simples e fadadas ao fim tornam-se, no texto literário do século XIX, uma questão de grandes proporções para suas vidas normais ${ }^{4}$.

\footnotetext{
"Hoje à noite não, meu caro amigo, estou na correria. Está chuviscando e minha alma está fedendo." (HUYSMANS, J.-K., Soixante-huit lettres inédites à Gabriel Thyébaut [inédito, consultável sob demanda pela Bibliothèque Nationale de France], Lettre XXIV, 16 décembre 1887, p. 54, tradução nossa)

2 MELVILLE, Herman. Bartleby, o escrevente. São Paulo, Grua, 2014, trad. Bruno Gambarotto, p. 27.

3 A aposentadoria de Senhor Bougran foi publicada postumamente, em 1964. Esta é a principal edição aqui consultada (HUYSMANS, Joris-Karl. La Retraite de Monsieur Bougran, Paris, Jean-Jacques Pauvert, 1964). Os trechos da novela aqui citados em português se referem à recente tradução da novela para o português de Marina Donato Scardoelli (A aposentadoria de Senhor Bougran, in [n.t.]: Revista Literária em Tradução, n. 14, v. 1, Florianópolis, set. 2017, p. 102-134. https://www. nota dotradutor.com/previas/(n.t.) Joris Karl Huysmans.html).

4 A condição do homem comum na literatura de ficção - se por "homem comum" entendermos aquele que não cumpriu nenhum feito extraordinário em vida ou que tampouco se esforça para tal - vem recentemente ganhando espaço na expressão romanesca contemporânea, a exemplo de escritores como Michel Houellebecq (A Extensão do Domínio da Luta, Seratonina) e Patrice Jean (L'homme surnumméraire), para citar dois exemplos de expressão francesa.
}

O caráter ordinário de Ivan Ilitch e Bougran, ambos funcionários públicos, desperta interesse justamente pela narrativa literária de sua existência como tais e não pela realização de feitos extraordinários. Ao suportar sua existência e ao deparar-se com a morte, tangem um certo heroísmo, mas um heroísmo banal, pelo qual todo ser humano passará. A morte desses funcionários públicos ultrapassa a dimensão profissional para adquirir a acepção de comunitária, no sentido de "comum" e "banal", em suma, daquilo que compartilham com os outros homens e que os iguala entre si. No confronto com a ideia de morte, dão-se conta de sua condição transitória, refletem sobre a própria observação do mundo e buscam ocupar com artifícios o espaço de tempo que os separa da morte. São esses artifícios, recursos narrativos textuais, que serão aqui abordados para a compreensão da figuração da morte sob a ótica de duas personagens do serviço público e do comum.

A gênese de $A$ morte de Ivan Ilitch e $A$ aposentadoria do Senhor Bougran reflete momentos de um certo fim na vida de seus autores, ou melhor, de um renascimento espiritual. A saber: a conversão inevitável ao cristianismo, discreta ou explicitamente onipresente na obra de Huysmans após sua convivência com o padre excomungado Boullan e a experiência satânica, retratados em Là-bas. Quanto a Tolstoi, seus escritos serão marcados por sua fé cristã idiossincrática e original, em busca do cristianismo primitivo, sobretudo após a crise mística decorrente de sua vivência traumática da Guerra da Criméia. Por fim, Tolstoi decidirá levar uma vida de ideais ascéticos e ao mesmo tempo comunitários, no seio da simplicidade rural. Alguns de 
seus escritos (Padre Sérgio, A Confissão, No que acredito, para citar apenas alguns) haveriam de desagradar a igreja ortodoxa russa a ponto de custar sua excomunhão em 1901.

Em ambas narrativas aqui tratadas, essas transformações vivenciadas pelos autores tomam a forma literária do cotidiano burguês laboral: dois personagens, funcionários ligados ao Estado, cujo trunfo é ter sobrevivido a suas próprias vidas e enfrentado a morte. Ivan Ilitch é um juiz de alta corte na Rússia, protagonista da narrativa que termina e começa com sua morte anunciada no jornal: "A história pregressa da vida de Ivan Ilitch foi das mais simples e comuns e, ao mesmo tempo, das mais terríveis ${ }^{5}$." Bougran, ex-burocrata ministerial em Paris, tem sua aposentadoria anunciada pelo chefe no início da novela. Inconformado com sua aposentadoria forçada, ele passa pela confirmação com o chefe a respeito do regulamento das leis referentes a aposentadoria "por invalidez moral". O código, as emendas e os artigos, Bougran - ironicamente - conhece de trás para frente.

Por "funcionário público" entendese aqui a definição de Boris Barraud, circunscrita ao século XIX e fundada na definição de Bouretz e Pisier, segundo a qual o funcionário público é todo agente que foi "nomeado em um emprego permanente a período integral e intitulado em uma escala da hierarquia das administrações ${ }^{6 \prime}$. Nesse âmbito laboral representado pelo gênero novelesco, duas

5 TOLSTOI, Lev. A morte de Ivan Ilitch, São Paulo, Ed. 34 (col. "Leste"), 2009, trad., posfácio e notas de SCHNAIDERMAN, Boris, p. 17

6 BOURETZ, P.; PISIER, E. Le Paradoxe du fonctionnaire, Calmann-Lévy, 1988, spéc. p.11, cit. in BARRAUD, Boris. "La taxinomie des fonctionnaires: entre l'art et l'obsession", Revue française de droit administratif, Dalloz, 2014, pp.269275, p. 271. acepções do termo latino labor convergem: a verbal e a nominal. $\mathrm{O}$ primeiro toma $\mathrm{o}$ sentido próprio e figurativo de "deslizar", "escorregar", "cambalear", "errar", "enganar-se", etc. O segundo tem o sentido nominal de "sofrimento", "dor" ou "fadiga que se experimenta na realização de um trabalho", ou ainda "esforço", enfim, o "labor" em si. Nessa polissemia do termo, o funcionalismo público se aproxima das agruras da vida do servidor público e de sua morte. A tríade "trabalho-vidamorte" inscreve-se como topos frequente na literatura do século XIX, analisado por Paul Gerbod: o funcionário público na sociedade reestruturada pós-revolucionária na França (e aqui consideramos também sua influência, política e cultural, sobre a Rússia daquela época ${ }^{7}$ ), motivo recorrente nessas duas expressões literárias nacionais, abundante tanto em reconhecimento e valorização quanto em crítica e ironia ${ }^{8}$.

Se a vida funcionalista permeia ambas narrativas, não sem um certo sentimento de absurdo experimentado pelas protagonistas, estes diferem quanto a seu envolvimento com o trabalho. Ivan Ilitch "possuía no mais alto grau esta capacidade de isolar o lado funcional, não o confundindo com sua vida verdadeira ${ }^{9 "}$ ao passo que Bougran, forçado a se apo-

\footnotetext{
O uso recorrente de galicismos e expressões francesas nesta novela de Tolstoi e em grande parte de sua obra (bem como em outros atores russos) revela a influência francesa sobre a Rússia no século XIX.

8 Vide: GERBOD, Paul. « Le fonctionnaire dans la littérature du XIXe au XXe siècle », Revue Administrative, 1999, p. 345. Terá sido essa a razão da aposentadoria precoce da novela em questão? Podem ser igualmente plausíveis as hipóteses lançadas por Maurice Garçon de que Huysmans terá retido seu manuscrito em razão da publicação de Bouvard et Pécuchet, de Flaubert, em 1880 na Nouvelle Revue, que virá a ser integralmente publicado em 1866; ou ainda em razão do romance Ronds de Cuir, de Courteline, no qual é questão a estreiteza da vida pública? Ronds de cuir remete ao termo pejorativo ao qual são referidos os funcionários públicos (Vide o prefácio de Maurice Garçon em La Retraite de Monsieur Bougran, op.cit., p. 18.

9 TOLSTOI, op.cit., p. 33.
} 
sentar, não vê mais sentido em viver longe de seu trabalho ministerial. Contudo, a vida de Ivan Ilitch, "em geral, continuava a desenvolver-se" de maneira "agradável e decentemente ${ }^{10 "}$ e ele atribuía importância essencial à sua profissão:

Mas o principal era o fato de existir a sua vida de funcionário. Todo o interesse da existência concentrou-se para ele no mundo judiciário. E este interesse absorvia-o. A consciência do seu poderio, da possibilidade de aniquilar qualquer pessoa, a imponência, mesmo exterior, ao entrar no tribunal e nas entrevistas com os subalternos, o seu êxito diante dos superiores e dos que Ihe eram subordinados e, sobretudo, a sua mestria em conduzir casos criminais, tudo isto alegrava-o e enchiaIhe a existência ${ }^{11}$.

A mesma essência laboral em vida é expressa na curta novela de Huysmans, notadamente os percalços mentais do funcionário público do ministério do Interior (cargo exercido pelo próprio Huysmans). Bougran se esforçará em continuar a existir através da prolongação simulada de sua profissão, transferida a seu lar nos mínimos detalhes, e poetizada no texto à maneira descritiva dos naturalistas, rica em detalhes sinestésicos. A intimação a uma aposentadoria precoce é o começo do fim do protagonista de $A$ aposentadoria de Senhor Bougran, que não deixa de remeter ao curioso personagem Bartleby em Bartleby, o escrevente, de Herman Melville, e à sua célebre fórmula: "I would prefer not to ${ }^{12 "}$. Bougran certamente preferiria não ter sido intimado a aposentar-se; gostaria de continuar a trabalhar febrilmente, como de fato o faz.

\footnotetext{
10 Ibid., p. 27.

11 Id., ibid.

12 Vide nota 2, p. 1.
}

Segundo Jean Borie, "[o] funcionalismo é a parte imersa da vida de Huysmans. Ele falou pouco em seus livros e quase não fez, a esse respeito, confidências a seus amigos. Seus biógrafos imitam sua discrição. ${ }^{13}$ " Não é de se surpreender que a novela nasce materialmente em papel in-fólio do ministério do Interior ${ }^{14}$ em que Huysmans trabalhava. No Cahier Vert ${ }^{15}$ (caderneta de anotações, inédita em sua integralidade) encontram-se esboços de ideias, datados do final de 1886 e que viriam a realizar-se em $A$ aposentadoria de Senhor Bougran:

Levado a aposentadoria, ele inventa para si casos a resolver. Ele corresponde. Guerra. Justiça. Redige cartas, as datas (ele só tem alguns minutos), vai aos escritórios onde manteve amigos para justificar o fundamento de suas resoluções - um traje de office boy o comove - tem caixas de papelão - sala administrativa - barato! Leva envelopes, etc. - antigos processos só para ele sai no horário do almoço, volta às 11 horas - folha de presença - priva-se

${ }^{13}$ BORIE, Jean. Huysmans: le diable, le célibataire et Dieu (Préface), Paris, Grasset et Fasquelle, 1991, p.10, tradução nossa).

${ }^{14}$ GARÇON, Maurice, Préface à La Retraite de Monsieur Bougran, op.cit., p. 18. Mais adiante, Maurice Garçon revela que Huysmans "havia levado, ao aposentar-se, uma grande quantidade de folhas de papel de carta com cabeçalhos do ministério e durante muito tempo usou-as para sua correspondência. Eu tive em mãos uma carta de 1899 na qual ele havia, com traços um pouco enraivecidos, colocado EX à frente do termo Ministério do Interior. Ele continuou a utilizá-los e, em um artigo publicado no Figaro a 20 de janeiro de 1900, o redator chamava a atenção ao fato de que ele ainda havia recebido cartas de J.K. com o cabeçalho oficial, mas que ele havia transformado, à mão, esse cabeçalho em "Ministério da Vida Interior." (Ibid., p. 20-21).

${ }^{15}$ Integralmente inédito, o Cahier Vert contém inúmeras anotações do autor, dentre as quais, impressões de viagens e esboços de ideias. Dois anos depois das anotações que futuramente comporiam La Retraite de Monsieur Bougran, em 1888, Huysmans desenvolve a narrativa. Solicitado por George Moore, inglês intimamente ligado à literatura e às artes francesas daquela época, representante de uma revista literária fundada por Harry Quilter, advogado e amador da literatura, The Universal Review, Huysmans propõe sua novela por intermédio de Edith Huybers (depois Reverdy). Sem êxito, a novela será guardada e jamais publicada em vida. 
de algo - a doce loucura da histeria administrativa - ah, ainda assim não é a ilusão inteira, morre disso (sic) ${ }^{16}$.

A representação da morte inevitável é representada nos textos como algo de banal, tanto para Ivan Ilitch quanto para Bougran. Seu sofrimento não advém da falta do trabalho em si, mas de um luto daquilo que o trabalho representa, o que remete à análise de Sigmund Freud (Sobre a Transitoriedade). Nele, o autor parte das observações melancólicas de um amigo poeta que se lamenta da transitoriedade da natureza durante um passeio por uma florida paisagem de verão. Plenamente circundado da beleza natural, o poeta medita em profunda melancolia sobre o fim e a transitoriedade das coisas, o que levará Freud refletir sobre a noção de luto:

O luto pela perda de algo que amamos ou admiramos se afigura tão natural ao leigo, que ele o considera evidente por si mesmo. Para os psicólogos, porém, o luto constitui um grande enigma, um daqueles fenômenos que por si sós não podem ser explicados, mas a partir dos quais podem ser rastreadas outras obscuridades. Possuímos, segundo parece, certa dose de capacidade para o amor - que denominamos de libido - que nas etapas iniciais do desenvolvimento é dirigido no sentido de nosso próprio ego. Depois, embora ainda numa época muito inicial, essa libido é desviada do ego para objetos, que são assim, num certo sentido, levados para nosso ego. Se os objetos forem destruídos ou se ficarem perdidos para nós, nossa capacidade para o amor (nossa libido) será mais uma vez liberada e poderá então ou substituí-los por outros objetos ou retornar temporariamente ao ego. Mas permanece um mistério para nós o

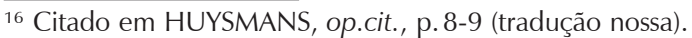

motivo pelo qual esse desligamento da libido de seus objetos deve constituir um processo tão penoso, até agora não fomos capazes de formular qualquer hipótese para explicá-lo. Vemos apenas que a libido se apega a seus objetos e não renuncia àqueles que se perderam, mesmo quando um substituto se acha bem à mão. Assim é o luto ${ }^{17}$.

Em A Morte de Ivan Ilitch e A aposentadoria de Senhor Bougran, esse objeto em questão é, dadas as devidas proporções, o trabalho e sua perda. O labor se manifesta, de modo fantasmático, no momento em que ambos escorregam do trabalho em direção à morte, que implica naquilo que Freud explica desse "processo tão penoso" advindo do "desligamento da libido de seus objetos". O luto se manifesta então, como misterioso, assim como a morte. Com o fim da vida de servidor público, modo de vida em que apostam sua existência sem necessariamente amá-lo, a ideia de luto pelo trabalho ganha espaço, desembocando, por fim, na morte em si.

A lembrança do silogismo da Lógica de Kiesewitter que perturba Ivan Ilitch em sua agonia é a percepção de sua condição mortal: "Caio é um homem, os homens são mortais, logo Caio é mortal". Este encadeamento lógico "parecera-lhe, durante toda a sua vida, correto somente em relação a Caio, mas de modo algum em relação a ele ${ }^{18 "}$. Se Ivan Ilitch e Bougran têm consciência de serem homens comuns e de exercerem profissões cuja falta de sentido é, paradoxalmente, o que confere

\footnotetext{
17 FREUD, Sigmund. Obras completas, vol, XIV, Rio de Janeiro, Ed. Imago, 1996, consultado em http://www.freudiana. com.br/destaques-home/sobre-transitoriedade.html a 15 de dezembro de 2018. Vide também FREUD, Sigmund. "Vergänglichkeit" [1916 (1915)], in Bildende Kunst und Literatur, vol. X, Frankfurt a.M., S.Fischer Verlag, 1969, pp. 223-227, aqui p. 226-227.

18 TOLSTOI, op.cit., p. 49.
} 
sentido às suas vidas, a morte é uma certeza incômoda até então não-manifesta.

No espaço vazio da falha entre a lógica clara e a percepção hesitante, entre o significante supostamente real dos objetos e seus sentidos estéticos polissêmicos, instaura-se a representação da morte nos dois textos de ficção. Neles, assim como a narrativa que abre o artigo de Freud, a condição particular do discurso literário ocupa um nicho entre a lógica (inteligível e compartilhada entre os seres humanos) e a experiência empírica (marcada por impressões estéticas que parecem manifestar-se como únicas e inalienáveis). Neste caso, o texto literário acomodase como não-lugar; um não-lugar assim como a morte. É precisamente ali que a representação de morte, compreensível apenas em sua essência de negação, se encaixa.

As duas narrativas tratam do preenchimento do curto tempo entre a vida e morte que resta a Ivan Ilitch e Bougran. Assim, ambos recorrem a artifícios para preencher o tempo de vida entre o fim do trabalho e a morte, confrontando dessa maneira a ideia de homem comum que foram: "[...] mas [Ivan Ilitch] não era Caio, não era um homem em geral, sempre fora um ser completa e absolutamente distinto dos demais ${ }^{19}$." Se há certa resistência em morrer, originária da sensação de não ser um homem como Caio, o funcionalismo reafirma, no entanto, o caráter ordinário de ambas personagens, o que em princípio deveria familiarizá-los com a própria morte. Não é o caso. A lógica de Kiesewitter soa perturbadora ao moribundo quando questionada por Ivan Ilitch: há uma diferença entre a compreensão da lógica e a carga estética evocada pelas memórias:

[...] [Ivan] era Vânia, com mamãe, com papai, com Mítia e Volódia, com os brinquedos, o cocheiro, a babá, depois com Katienka, com todas as alegrias, tristezas e entusiasmos da infância, da juventude, da mocidade. Existiu porventura para Caio aquele cheiro da pequena bola de couro listada de que Vânia gostara tanto?! Porventura Caio beijava daquela maneira a mão da mãe, acaso farfalhou para ele, daquela maneira, a seda das dobras do vestido da mãe? Fizera um dia tanto estardalhaço na Faculdade de Direito, por causa de uns pirojki? Estivera Caio assim apaixonado? E era capaz de conduzir assim uma sessão de tribunal?20

A descrição de tais artifícios que contornam a morte remete a objetos e lembranças sensoriais que, para cada uma das personagens, são únicas e inalienáveis e que fazem com que Ivan Ilitch se separe da consciência de mortalidade. Ele se recorda do gosto do caroço da ameixa, proustianamente avant la lettre, o que Ihe desencadeia uma nova série de lembranças:

Apareciam-lhe, um após o outro, os quadros do seu passado. Isto começava sempre pelo que estava mais próximo no tempo e ia dar sempre no mais distante, na infância, onde se detinha. Se Ivan Ilitch lembrava a ameixa seca cozida que lhe ofereciam agora para comer, vinha-lhe também à memória a ameixa seca crua francesa, enrugada, da sua infância, o seu gosto peculiar e a abundância de saliva quando se chegava ao caroço, e a par dessa recordação de um sabor, surgia toda uma série de recordações daquela época: a ama-seca, o irmão, os brin- 
quedos. "Não devo pensar nisso... é doloroso demais" - dizia Ivan Ilitch a si mesmo e tornava a transportar-se para o presente. Um botão nas costas do divã e rugas no marroquim. "O marroquim é caro, pouco resistente; foi causa de uma briga. Mas houve também outro marroquim e outra briga [...]." E de novo aquilo detinha-se na infância, e mais uma vez Ivan Ilitch sentia dor e procurava repelir aquelas imagens e pensar em outra coisa ${ }^{21}$.

Ivan Ilitch, assim como Bougran, também se atém a detalhes, descritos nas narrativas sob certa técnica literário realista, detalhes esses que remetem as personagens ao passado, como mobília e os objetos decorativos "comme il faut ${ }^{22 " . ~}$ A mobília, descrita com precisão e com certa recorrência tanto por Huysmans quanto por Tolstoi, evoca no caso de Bougran o universo burocrático, outro significante da vida no qual se realiza a linguagem administrativa, tão marcante para a personagem de Huysmans. Recémdemitido, Bougran reproduz em sua casa, nos mínimos pormenores, o ambiente de trabalho deixado para trás, o que por sua vez se assemelhará da mesma maneira, também avant la lettre, à célebre madeleine proustiana através do estímulo sensorial, reproduzido em seu lar:

Sobre a escrivaninha, organizou, em uma ordem metódica, toda a série de suas canetas-tinteiro e lápis; canetatinteiro em forma de bastão, em cortiça, caneta-tinteiro de revestimento de cobre combinado com pau-rosa, que cheirava bem quando mascado, lápis pretos, azuis, vermelhos, para as notas e observações. [...] Processos em papel amarelado quase em todo lugar; em

\footnotetext{
21 Ibid., p. 69.

22 Em francês, no original, "como é preciso. Há três recorrências da mesma expressão na narrativa.
}

cima das caixas, os livros necessários: o Dicionário de Administração de Bloch, o Código e as Leis Usuais, Béquet, Blanche"; encontrava-se, sem ter mudado de lugar, de volta a seu antigo escritório, à sua antiga sala ${ }^{23}$.

Aquilo que para Bougran simula a vida e o faz escapar da morte atormenta, por outro lado, Ivan Ilitch nos momentos finais: a lembrança do ambiente de trabalho. Moribundo, Ivan Ilitch interroga a si mesmo:

"E o que tu queres agora? Viver? Viver como? Viver como tu vives no tribunal, quando o meirinho proclama: 'Está aberta a sessão!...' Está aberta a sessão, a sessão" - repetiu consigo. - Aí está o julgamento! Mas eu não tenho culpa! exclamou com raiva. - Por quê? - parou de chorar e, voltando o rosto para a parede, pôs-se a pensar no mesmo: por quê, por que todo esse horror ${ }^{24}$

Ivan Ilitch morre por trabalhar, enquanto que Bougran morre trabalhando, pois viveu e trabalhou morrendo. Em passagem não desprovida de certa comicidade narrativa, Bougran vislumbra a morte desde o início da narrativa. Ela ocorre à noite, em meio aos gritos dos funcionários contratados para seu escritório artificial (um funcionário assistente do Ministério e a empregada doméstica), em cima de uma folha de papel sobre a escrivaninha, na qual escrevera às pressas,

\footnotetext{
23 "Sur son bureau, il rangea, dans un ordre méthodique, toute la série de ses porte-plume et de ses crayons, porte-plume en forme de massue, en liège, porte-plume à cuirasses de cuivre emmanchés dans un bâton de palissandre, sentant bon quand on le mâche, crayons noirs, bleus, rouges pour les annotations et les renvois. [...] Des dossiers de papier jaunâtre un peu partout; au-dessus des casiers, les livres nécessaires: "Le Dictionnaire d'Administration de Bloch, Le Code et les Lois usuelles, le Béquet, le Blanche"; il se trouvait sans avoir bougé de place, revenu devant son ancien bureau, dans son ancienne pièce." (HUYSMANS, op.cit., p. 51; trad.cit., p.128).

${ }^{24}$ TOLSTOI, Ibid., p. 68.
} 
pressentindo seu fim: "'Por esses motivos, não posso, Senhor Presidente, senão emitir um parecer desfavorável sobre dar continuidade ao recurso formulado por um cavalheiro tal.'25"

A desocupação incarna para Bougran a maior ameaça trazida pela aposentadoria; implica uma situação em um espaço difícil de suportar, entre a vida e a morte ${ }^{26}$. Para Bougran, contornar a morte proferida pela aposentadoria consiste, diferentemente de Ivan Ilitch, em reproduzir obsessivamente a vida burocrática de antes:

Inventava questões a tratar, enviava a si mesmo petições, respondia, fazia o que chamamos de 'registro', escrevendo em um livro grande a data dos recebimentos e dos envios. $\mathrm{E}$, com a sessão de escritório terminada, vagava, como antes, uma hora nas ruas antes de retornar para jantar ${ }^{27}$.

Ivan Ilitch, por sua vez, não deixava que a vida profissional tomasse completamente o controle de sua vida pessoal, o que para ele implicava "repelir o humano", conferindo-lhe uma condição artificialmente virtuosa e forte:

[...] permitia-se às vezes como que misturar, brincando, as relações humanas e funcionais. Permitia-se isto porque sentia em si forças suficientes, sempre que lhe era necessário destacar apenas o funcional e repelir o humano. Esta operação desenvolvia-se para Ivan Ilitch não só leve, agradável e decentemente, mas até com virtuosismo ${ }^{28}$.

25 HUYSMANS, op.cit., p. 65; trad.cit., p. 134.

26 [...] la retraite met un espace, souvent difficile à supporter, entre la vie et la mort. (RMB, p. 8)

27 HUYSMANS, op.cit., p. 52; trad.cit., p. 128: "Il s'inventait des questions à traiter, s'adressait des pétitions, répondait, faisait ce qu'on appelle "I'enregistrement", en écrivant, sur un gros livre la date des arrivées et des départs. Et, la séance de bureau close, il flânait comme autrefois une heure dans les rues avant que de rentrer pour dîner".

28 TOLSTOI, op.cit., p. 33.
Estabilidade e harmonia são as diretrizes do serviço público, seja para o juiz Ivan Ilitch, seja para o funcionário Bougran e, a julgar pelas personagens, ambas dependem de maneiras distintas do trabalho para viver. Seja o trabalho como meio de sustentar a si e a sua família (Ivan Ilitch), seja a colocação de sentido na vida do homem solteiro por meio do trabalho (Bougran), a ausência de sentido espelha o a morte. Esse cotidiano banal torna-se cerne da própria intriga e do discurso das duas novelas, antecipando assim, no caso de Huysmans, o tratamento da literatura de ficção do nouveau roman ${ }^{29}$, a exemplo de A Náusea, de Jean-Paul Sartre, romance em que soam ecos huysmansianos. Em A aposentadoria do Senhor Bougran, o discurso administrativo se manifesta como antípoda à literatura de ficção, e realiza-se na pintura do cotidiano banal, já explorada pelos realistas e naturalistas.

Não sendo exatamente anti-heróis, Bougran e Ilitch alegorizam estabilidade e harmonia que levam a seu isolamento, bem como a um ideal de realização comum que Ihes escapa em vida. Para esses nãoheróis, se assim pudermos designá-los, as convenções e normas - sociais e laborais - confrontam a magnitude do naturalismo, de tendência documental e macroscópica, para confinar-se numa esfera que em sua forma evoca, contudo, o naturalismo. O foco narrativo se direciona ao universo individual do funcionário público, seja este um solteiro convicto como BougranHuysmans ou um homem casado como Ivan Ilitch-Tolstoi. Aliás, é impossível para Ivan Ilitch arcar com a amplitude do

\footnotetext{
${ }^{29}$ A respeito de paralelos possíveis entre a narrativa huysmansiana e o nouveau roman, vide BERTHIER, Philippe. "La débâcle du genre", in Huysmans à côté et au-delà, Leuven-Paris, PeetersVrin, 2001, p. 27.
} 
romance naturalista de um Zola quando reflete sobre seu estado natural do ponto de vista fisiológico, a suposta doença no ceco:

[...] Ivan Ilitch estava naquela noite mais alegre que outros dos presentes, mas ele não esqueceu um instante sequer que tinha importantes pensamentos, deixados de lado, a respeito do seu ceco. Despediu-se às onze horas, a fim de se recolher. Desde o início da doença, dormia sozinho, num quartinho junto ao seu escritório. Foi para ali, despiuse, apanhou um romance de Zola, mas não o leu, e ficou pensativo. E em sua imaginação ocorria aquela correção desejada do seu $\mathrm{Ceco}^{30}$.

O recurso homeopático, cogitada por Ivan Illitch após ter consultado outros médicos a fim de tratar sua doença, não havia apresentado resultados positivos e fora, assim como o romance de Zola, deixada de lado ${ }^{31}$. O conhecimento científico alopático também se revela ineficaz contra a inquietude que o aflige: "O seu estado ainda era agravado pelo fato de ler livros de Medicina e se aconselhar com médicos ${ }^{32 "}$. Afinal, de que serve a leitura - de livros científicos e até mesmo do romance naturalista de Zola - se o seu corpo torna-se sua única preocupação e se apenas o pensamento da morte iminente o assombra? Ivan Ilitch havia compreendido: "E de repente, o caso se Ihe apresentou por uma face completamente oposta. 'O ceco! O rim - disse a si mesmo. - O caso não está no ceco, nem no rim, mas na vida e...na morte. Sim, a vida existiu, mas eis que está indo embora, embora, e eu não possa detê-la'.33" Para Ilitch, os livros e a

\footnotetext{
30 TOLSTOI, op.cit., p. 46.

31 Ibid., p. 41.

32 Ibid., p. 40.

${ }^{33}$ Ibid., p. 47.
}

ciência perdem o sentido perante a morte iminente à qual não há resposta.

Já para Bougran, ao contrário, a linguagem é o único sentido possível, pois é tudo o que conhece. A solução "homeopática" também é mal lograda para Bougran. Embora sofra pela ausência do escritório, não se pode exatamente dizer que o flegmático Bougran tenha amado suas tarefas de funcionário público. Mas essas tarefas davam o significado à sua vida. Nem bem foi demitido, o tédio sentido no escritório lhe faz falta. Passeios, visitas a museus e contemplações de obra de arte, nada disso lhe serve. Trata-se de um problema de codificação: Bougran, conhecendo a linguagem administrativa, não entende a semiótica das cores e das formas, não aprecia o código artístico, como observa Arnaud Vareille:

É de fato [...] "cansado de cores" (p.47) que Bougran sai dos museus, onde "não conhecia tela alguma, mestre algum" (p.46-47), pois as cores das telas são ininteligíveis para ele e exigem um esforço de conhecimento e de raciocínio para que percebe o sentido. Ora, Bougran não dispõe do código que lhe assegura legibilidade, código ainda menos acessível para ele que, ao contrário daquele monossêmico da administração, é polissêmico, já que a obra de arte não se deixa reduzir a um discurso pré-construído ${ }^{34}$.

Somente resta a Bougran, cujo trabalho baseia-se em fórmulas administrativas

\footnotetext{
34 "C'est bien [...] 'las de couleurs' (p.47) que Bougran ressort des musées, où 'il ne connaissait aucune toile, aucun maître' (p.46-47), car les couleurs des tableaux lui sont inintelligibles et nécessitent un effort de connaissance et de raisonnement pour en percevoir le sens. Or, Bougran ne dispose pas du code en lui assurant la lisibilité, code d'autant moins accessible pour lui que, contrairement à celui monosémique de l'administration, il est polysémique, l'oeuvre d'art ne se laissant pas réduire à un discours pré construit." VAREILLE, Arnaud. "Les rituels de M. Bougran", in J.-K. Huysmans: littérature et religion (coll. "Interférences"), pp.139-154, Rennes, Presses Universitaires de Rennes, 2009, p. 144 (tradução nossa).
} 
conhecidas, tentar ocupar o espaço vazio, intolerável entre a aposentadoria e a morte através da reprodução contínua do que fora até então: funcionário burocrata. Combater a ausência do escritório e o sentimento de iminência do fim - a aposentadoria forçada - acelera a morte. Combater a doença com o agente causador da própria doença, que é o caminho homeopático, revela-se uma empreitada mal lograda.

Em A aposentadoria de Senhor Bougran (o termo "bougran" significa justamente "entretela", "talagarça"), o caráter nãoheroico do protagonista se reflete em suas práticas discursivas: na incapacidade de abandonar o jargão administrativo, que ele deplora, embora não consiga abdicar a ele. Entre o fim da vida laboral e a morte, entre a linguagem que despreza mas da qual não consegue abrir mão; o mal que o aflige é a falta do escritório. Esta será suprida não apenas pelo simulacro ministerial em casa, mas sobretudo pela memória da linguagem administrativa, que para Bougran parece adquirir o estatuto de "língua":

Ah, essa língua administrativa da qual deveria cuidar! Esses "respaldar-se de", "em resposta à carta que recebi, tenho a honra de informar que", esses "conforme o parecer apresentado em sua missiva relativa a...". Essas frases costumeiras: "o espírito, senão o texto da lei", "sem desmerecer a importância das considerações invocadas para sustentar esta tese...". Enfim, essas fórmulas destinadas ao ministério da Justiça em que se falava do "parecer emanado de sua Chancelaria". Todas essas frases evasivas e atenuadas, os "estou inclinado a acreditar", "não lhe escapará", "fixarei o preço em", todo esse vocabulário de volteios que remonta ao tempo de Colbert deixava Sr. Bougran agoniado ${ }^{35}$.

\footnotetext{
35 "Ah! cette langue administrative qu'il fallait soigner! Ces 'exciper de', ces 'En réponse à la lettre que vous avez bien voulu m'adresser, j'ai l'honneur de vous faire connaître que',
}

A obra de Huysmans é marcada pela influência das expressões mais particulares da literatura, bem reveladas pelo gosto literário da personagem Des Esseintes em Às avessas. O apreço por uma expressão literária injustamente esquecida, de mestres mais ou menos obscuros, manifestado laudatoriamente por Des Esseintes, reflete a inclinação de Huysmans por uma literatura do isolamento. Na quase totalidade de sua obra, a tebaida é parte fundamental. A ascese, bastante diferente da de Tolstoi, costuma ser para Huysmans, como o nome indica, um exercício estético e espiritual. Raramente há nítida separação entre essas categorias. As tebaidas em Huysmans, da aventura estética de Às avessas à oblatura do ciclo dos romances de Durtal prenunciam uma tendência mística dos escritos de Huysmans e do próprio autor ${ }^{36}$. A aposentadoria de Senhor Bougran, cuja desentoação do conjunto da obra é apenas ilusória, não é uma exceção. A história do "Senhor Entretela" é marca de uma passagem mais ou menos estabelecida à religião católica, sem que o naturalismo seja de todo abandonado. Tomando forma de ascese (inclusive no sentido original de

ces 'Conformément à l'avis exprimé dans votre dépêche relative à...'. Ces phraséologies coutumières: 'l'esprit sinon le texte de la loi', 'sans méconnaître l'importance des considérations que vous invoquez à l'appui de cette thèse...'. Enfin ces formules destinées au Ministère de la Justice où I'on parlait de 'I'avis émané de sa Chancellerie', toutes ces phrases évasives et atténuées, les 'inclinerais à croire', les 'il ne vous échappera pas', les 'j'attacherais du prix à', tout ce vocabulaire de tournures remontant au temps de Colbert, donnait un terrible tintouin à M. Bougran. (HUYSMANS, op.cit., p.61; trad.cit., p.132).

36 A correspondência de Huysmans revela um caráter preciso e pontual do autor (principalmente nas cartas a Léon Bloy, a Villiers de I'Isle-Adam e ao desconhecido Gabriel Thyébault), da mesma maneira que seus biógrafos atestam que, a não ser pelo modus operandi emprestado à rotina burocrática, Huysmans nunca sacrificou suas tarefas oficiais pelas literárias. O gosto pela documentação histórica e ocultista, amplamente reproduzido em Là-bas, a pesquisa sobre a simbologia cristã em La Cathédrale, bem como as anotações e as incursões em sebos mostram de fato uma tendência à organização e à ordem documental burocrática. 
"exercício"), as escrituras burocráticas (e não da "écriture" literária), assim como o documento funcional (e não o documento literário) operam na narrativa em forma de alegorias para a personagem Bougran. Ele escreve somente em função da administração pública, pois desconhece - para usar um termo burocrático abstruso que certamente desagradaria ao personagem - a vida extraministerial.

Maurice Garçon, responsável por exumar e publicar postumamente $A$ aposentadoria de Senhor Bougrain, recorda uma série de confissões epistolares e jornalísticas de Huysmans a respeito da importância que o cargo de funcionário exercia sobre ele, bem como um certo distanciamento irônico de sua profissão de "rond de cuir", termo pejorativo para servidores públicos na França do século XIX. Por que, então, a aposentadoria forçada de representaria uma prémorte para Bougran? Assim como para Huysmans, a vida administrativa, não obstante o tédio que ela comporta (ou talvez justamente por causa desse tédio), apresenta-se como um porto seguro, o que não implica um desejo de inserção naquele mundo. Trata-se apenas de uma tendência ao isolamento, a um louvor da intimidade. A aposentadoria e a liberdade que ela potencializa se desdobrariam em uma antecâmara da morte para Bougran fora do ministério. A visão de mundo profissional, sentimento cumprido por ele, não difere muito daquela de Huysmans, cuja correspondência revela a esse respeito uma aproximação com um inferno e, portanto, com a morte:

Estou em um tédio sombrio com meu maldito Ministério. O combinado que eu havia mencionado, a perspectiva de um cargo de subchefe, tudo caiu por terra, às migalhas - alguém vindo de fora ocupou o cargo do chefe, que por direito era do meu amigo. - Depois, meu escritório foi cortado em troços; enfim, estou amarrado como um cão, não posso tirar uma folga, é o inferno - e tudo isso sem lucro, sem futuro. Nessas condições, solicitei minha mudança de Direção, pois não quero ficar com o senhor que foi encarregado de ser meu chefe, tampouco faço questão de cumprir o trabalho de todo o escritório, a olho. Eu estou agitado como o diabo, mas não consigo nada [... $]^{37}$.

Pouco antes de sua conversão ao cristianismo, o escritório cumpria a função, posteriormente procurada, do claustro beneditino. Na correspondência pessoal de Huysmans encontram-se confidências sobre suas agruras ministeriais e a falta da repartição pública:

Não posso mais viver em paz em minha casa e como escreveria um livro agora que não tenho mais meu pequeno gabinete solitário com meu mata-borrão discreto atrás dos grandes escaninhos verdes e minha janela clara dando para os amplos jardins do ministério onde eu seguia e o florescimento dos botões e o voo das últimas folhas ${ }^{38}$.

\footnotetext{
37 "Je suis dans un noir ennui, avec mon damné Ministère. La combinaison dont je t'avais parlé, la perspective d'un souschefat, tout est par terre, en miette - quelqu'un est venu dehors qui a pris la place de chef à laquelle avait droit mon ami. - Puis, mon bureau a été coupé en tronçons, bref, je suis tenu à I'attache comme un chien, je ne puis avoir un congé, c'est l'enfer - et tout cela, sans profit, sans avenir. Dans ces conditions, j'ai demandé mon changement de Direction, ne voulant point rester avec le Monsieur qui m'est dévolu comme chef et ne tenant point à faire le travail de tout le bureau, à I'oeil. Je suis démené, en diable, mais je n'obtiens rien [...]." MORGAN, Owen. "Deux lettres inédites de J.-K. Huysmans à Léon Hennique", in Bulletin J.-K. Huysmans, n 72 (1981), p.54, tradução e grifo nossos. O uso de maiúsculas está em conformidade com o original).

38 "Je ne puis plus vivre en paix chez moi et comment écrirais-je un volume maintenant que je n'ai plus mon petit cabinet solitaire avec mon buvard discret derrière les gros cartonniers verts et ma fenêtre claire ouvrant sur les vastes jardins du ministère où je suivais et I'épanouissement des bourgeons et I'envol des derniers feuilles." DEVOS, Denise e BOUTEILLER, Paul. "J.K. Huysmans, fonctionnaire au Ministère de l'Intérieur de 1866 à 1898", in Bulletin de la Société J.K. Huysmans, n. 88,1995, p. 18.
} 
O fantasma da aposentadoria é representado na passagem memorável em que Bougran, frustrado, descreve a vegetação no Jardim do Luxemburgo. O motivo vegetal, caro a Huysmans, simboliza em $A$ aposentadoria de Senhor Bougran, o estado de espírito do aposentado abatido e evoca um forçamento do jardim, antinatural:

A relva espalhava sua cabeleira aparada curta e verde, as pequenas árvores balançavam a plumagem entediada de suas copas, mas, em alguns canteiros, a tortura infligida às árvores frutíferas o detinha. Essas árvores não tinham mais forma de árvores. Desmembravam-nas com varas metálicas, faziam-nas rastejar pelas hastes sobre o solo; desviavam seus membros desde o nascimento e obtinham, assim, vegetações acrobatas e troncos desarticulados, como de borracha $^{39}$.

As plantas simbolizam claramente o estado de espírito de Bougran, têm sua existência tolhida e direcionada como sua e são forçadas como a linguagem administrativa. O cenário desolador do jardim é como a vida ministerial. A narrativa prossegue explicando de maneira bastante didática e clara a falta de sentido e de graciosidade da vida burocrática, que reflete a incoerência da vida e da morte na observação das árvores:

Mas, depois de ter admirado essa forma de assassinar as árvores, sob o pretexto de extrair os melhores frutos, passava o tempo sem ter o que

\footnotetext{
39 "Les gazons y étalaient leurs cheveux coupés ras et verts, les petits arbres y balançaient les plumeaux ennuyés de leurs têtes, mais la torture infligée, dans certaines plates-bandes, aux arbres fruitiers l'arrêtait. Ces arbres n'avaient plus forme d'arbres. On les écartelait le long des triangles, on les faisait ramper le long de fils de fer sur le sol; on leur déviait les membres dès leur naissance et l'on obtenait ainsi des végetations acrobates et des troncs désarticulés, comme en caoutchouc." (HUYSMANS, op.cit., p. 44; trad.cit., p. 125).
}

fazer, sem mesmo perceber que essa cirurgia herbácea representava o mais perfeito símbolo da administração tal qual havia praticado durante anos. No escritório, como no jardim do Luxemburgo, tentava-se desmantelar coisas simples; pegava-se um texto de direito administrativo cujo sentido era límpido, claro, e imediatamente, com a ajuda de memorandos confusos, de precedentes sem analogia e jurisprudências que vinham do tempo da Revolução Francesa, fazia-se desse texto uma bagunça, uma literatura de Bárbaros, grotesca, com frases contorcidas, tornando as deliberações jurídicas opostas a tudo o que se podia prever $^{40}$.

A artificialidade, mortal quando imputada à natureza, é evocada de maneira semelhante por Thomas de Quincey em Suspiria de Profundis ao citar a expressão de Valério Flaco (viridantem floribus hastas $=$ "tornando as hastes verdejantes de flores"). A morte da própria natureza é deplorada pelo fato de que o material da haste usada para direcionar as flores provém da madeira, portanto, da própria natureza:

Não foram as ruas que se intrometeram nos ladrilhos, foram aqueles malditos ladrilhos que vieram aprisionar as ruas. O mesmo vale para a haste feia - haste de ópio, haste da videira, espaldeira, qualquer coisa que estiver ali para sustentar. As flores não estão

\footnotetext{
40 "Mais quand il avait bien admiré cette façon d'assassiner les arbres, sous le pretexte de leur extirper de meilleurs fuits, il traînait, désoeuvré, sans même s'être aperçu que cette chirurgie potagère présentait le plus parfait symbole avec l'administration telle qu'il l'avait pratiquee pendant des ans. Dans les bureaux, comme dans le jardin du Luxembour, I'on s'ingéniait à démantibuler des choses simples; I'on prenait un texte de droit administratif dont le sens était limpide, net, et aussitôt, à l'aide de circulaires troubles, à l'aide de précédents sans analogie, et de jurisprudences remontant au temps des Messidors et des Ventôses, aux phrases grimaçantes, rendant les arrêts les plus opposés à ceux que I'on pouvait prévoir." (HUYSMANS, op.cit., p 45; trad.cit., p.125).
} 
para a haste, mas a haste está para as flores. Quanto à mesma analogia, veja-me como um (nas palavras de um verdadeiro e mais inflamado poeta) viridantem floribus hastas fabricando, frondosas e alegres com a vida das flores, lanças assassinas e alabardas coisas que expressam morte em sua origem (feitas de substâncias mortas que antes viviam nas florestas), coisas que expressam ruina em seu uso $^{41}$.

A essa melancólica observação da natureza de Bougran e De Quincey, os motivos vegetais também fazem parte, de maneira menos sensível, da escolha decorativa de Ivan Ilitch, em compatibilidade a sua condição burguesa. A artificialidade de sua existência se exprime no gosto decorativo, compartilhado com outros homens "de determinado tipo":

[...] havia ali o mesmo que há em casa de todas as pessoas não muito ricas, mas que desejam parecê-lo e por isto apenas se parecem entre si: damascos, pau-preto, flores, tapetes e bronzes, matizes escuros e brilhantes; enfim, aquilo que todas as pessoas de determinado tipo fazem para se parecer com todas as pessoas de determinado tipo ${ }^{42}$.

Para Ivan Ilitch, o estado moribundo e a morte têm carga social que não existe para Bougran. Este não antevê a morte da

\footnotetext{
41 "The streets did not intrude amongst the bricks, but those cursed bricks came to imprison the streets. So, also, the ugly pole-hop-pole, vine-pole, espalier, no matter what is there only for support. Not the flowers are for the, pole, but the pole is for the flowers. Upon the same analogy, view me as one (in the words of a true and most impassioned poet ${ }^{1}$ ) "viridantem floribus hastas" making verdant, and gay with the life of flowers, murderous spears and halberts-things that express death in their origin (being made from dead substances that once had lived in forests), things that express ruin in their use." (DE QUINCEY, Thomas. Suspiria de Profundis, in The Confessions of an English Opium-Eater and other writings, Nova lorque, Oxford University Press, 2008, p. 94.

${ }^{42}$ TOLSTOI, op.cit., p. 31
}

mesma maneira que o primeiro. Se a luta de Bougran é a reprodução de um único modus vivendi concebível e ocupar o tempo de vida que Ihe resta, a luta de Ivan Ilitch é lembrar-se da vida para contornar a doença e a morte :

E ele convocava, um após o outro, pensamentos que substituíssem aquele, na esperança de encontrar neles apoio. Tentava voltar aos velhos caminhos de pensamento, que ocultaram para ele anteriormente a ideia da morte. Mas, fato estranho, tudo o que antes ocultava, escondia, anulava a consciência da morte, não podia mais ter este efeito. Ultimamente, Ivan Ilitch passava a maior parte do tempo nessas tentativas de restabelecer os primitivos caminhos do sentimento que ocultava a morte ${ }^{43}$.

Mas Ivan Ilitch também recorre ao trabalho como artifício para manter-se em vida:

Às vezes, dizia consigo: "Vou ocuparme do serviço, bem que ele já me faz viver". E ia para o tribunal, repelindo todas as dúvidas; iniciava conversas com os colegas e sentava-se, fazendo passar, segundo um velho hábito, o olhar distraído e pensativo sobre a multidão, e apoiando os braços emagrecidos nos braços da poltrona de carvalho, inclinando-se como de costume na direção do colega, empurrando para ele o processo, conversando em murmúrio, e depois, levantando de repente os olhos e ficando ereto na poltrona, proferia as palavras conhecidas e dava início ao julgamento ${ }^{44}$.

A tomada de consciência da morte para Ivan Ilitch se dá gradualmente, ao passo que a de Bougran ocorre através

\footnotetext{
43 Ibid., p. 50

${ }^{44}$ Id., ibid.
} 
da experiência estética. Entre a cognição lógica do silogismo de Kiesewitter e o decorrer da natureza, existe uma zona cinzenta, uma espécie de limiar que é o indivíduo e que questiona as verdades absolutas e que conduz ao sentimento de absurdo.

Em $A$ aposentadoria de Senhor Bougran e na correspondência de Huysmans, são frequentes passagens sobre chuva e o mau-tempo, diretamente associados à esqualidez do escritório:

Preciso dizer-lhe a vida que eu levo, a mediocridade absurda do escritório, da table d'hôte, da noitada, por esses tempos úmidos e escuros que deixam o ar dos quartos úmidos e sinistros. Enquanto não tiverem acendido a lareira, os apartamentos terão a alegria amável dos quartos mobiliados ${ }^{45}$.

O sentimento de absurdo, próximo ao universo cinzento, ministerial, doméstico e natural, da novela e relatado na correspondência de Huysmans prenunciam o "tédio sombrio" e a morte. Tal sentimento, originário da previsibilidade e do mecanismo sem sentido da função administrativa, desembocará no sentimento de luto pelo objeto amado, analisado por Freud e, por fim, na própria morte.

Tanto em Bougran quanto em Ivan Ílitch, a morte é antecedida por um desejo de isolamento e por uma nostalgia estética que já não tem mais lugar. Os rituais de trabalho, narrados com condescendência ao serviço público, diferentemente de Bougran, remetem a uma neutralidade laboral, linguística e autoritária:

\footnotetext{
$\overline{45}$ "Ai-je besoin de vous dire I avie que je mène, I'absurde médiocrité du bureau, de la table d'hôte, de la soirée, par ces temps humides et noirs qui font les chambres moites et sinistres. Tant qu'on n'aura pas allumé du feu, les appartements auront l'aimable gaieté des chambres garnies." (HUYSMANS, lettre VII, 26 octobre 1882, in Soixante-huit lettres inédites à Gabriel Thyébaut, op.cit., p. 27).
}

Ivan Ilitch jamais abusou desta sua autoridade e, pelo contrário, procurava atenuar a sua manifestação; mas a consciência dessa autoridade e a possibilidade de atenuá-la consistiam para ele o interesse principal e a atração de seu novo encargo. Quanto ao serviço propriamente dito, isto é, aos processos de instrução, Ivan Ilitch assimilou muito depressa os meios de afastar de si todas as circunstâncias estranhas, bem como os de enquadrar mesmo os casos mais complicados numa forma graças à qual se apresentassem no papel apenas externamente, excluído de todo o ponto de vista pessoal de Ivan Ilitch e, sobretudo, se cumprissem todas as formalidades exigidas ${ }^{46}$.

O serviço público é representado nas duas narrativas como uma área cinzenta - suscitando por vezes inclusive sensações de cores e de letras cinzentas e amargas -, como um espaço entre dois lugares, entre o aqui e o lá, entre a vida e a morte. Tal definição de espaço, bem como o penchant de Huysmans pela claustrofilia foi observada por Gilles Bonnet ${ }^{47}$, desde os romances "fotográficos" e quase impressionistas como Les Soeurs Vatard, ao experimento antinaturalista em Às avessas, o desejo de lugares e personagens situados em um entre-local, um local diferente, entre pares binários opostos. É somente na tebaida, termo usado tanto para a aventura estética de Des Esseintes quanto para o tédio de Bougran, que o texto literário se acomoda. Fadada à morte, a tebaida é desejada, mas mal lograda. A solidão impossível.

Ademais, a experiência do simulacro - o simulacro vegetal lamentado por Bougran e De Quincey na natureza,

\footnotetext{
46 TOLSTOI, op.cit., p. 21-22.

47 BONNET, Gilles. "HUYSROMANS : poétique du seuil", pp.103-115, in Huysmans et les genres littéraires,ed. BONNET, Gilles e SEILLAN, Jean-Marie, Rennes, Presses Universitaires de Rennes, 2010, p. 112.
} 
mas reproduzido por ele em casa - é uma mudança sintagmática da obra de Huysmans. Por exemplo, o tédio de Des Esseintes em comparação ao de Bougran não são essencialmente diferentes. A tartaruga cravejada de pedras preciosas em Às avessas se transpõe ao delírio taxomaníaco de Bougran em sua obsessiva reprodução do espaço da repartição pública em sua própria casa. Gilles Bonnet define esse espaço vazio, literário e sentimental, por terceiro lugar do limiar:

À oposição maniqueísta dentro/fora, que parece tão pertinente para uma apreensão do imaginário huysmansiano, é preciso sem dúvida preferir no contexto de uma tomada em conta da economia do romance - e portanto da sintagmática da narrativa, marcada, viu-se pela derrota final da clausura -, um modelo triádico que reconheceria um espaço intersticial de tenção onde o dentro e o fora viriam enfrentar-se ${ }^{48}$.

O mesmo desejo de ordem também se manifestava em Ivan Ilitch:

Tudo isto despertava-lhe tamanho interesse que mesmo o novo emprego distraía-o menos do que ele esperava, não obstante a sua afeição por esse tipo de trabalho. Durante as sessões, sobrevinham-lhe momentos de distração: ficava pensativo, conjeturando sobre o tipo de cornija mais conveniente para as cortinas - reta ou com saliência. Ficava tão absorvido com isto que, frequentemente, atarefava-se pessoalmente, mudava até a posição da mobília e pendurava as cortinas ${ }^{49}$.

\footnotetext{
48 À l'opposition manichéenne dedans/dehors, qui paraît si pertinente pour une appréhension de l'imaginaire huysmansien, il faut sans doute préférer dans le cadre d'une prise en compte de l'économie du roman et donc de la syntagmatique du récit, marquée, on I'a vu par la défaite finale de la clôture, un modele triadique qui reconnaîtrait un espace interstitiel de tension où le dedans et le dehors viendraient s'affronter. (BONNET, art.cit., p. 107).

49 TOLSTOI, op.cit., p. 30.
}

A linguagem pronta, proferida por Ivan Ilitch e febrilmente escrita por Bougran serve-lhes de resistência para manterem-se vivos. A transitoriedade da vida à morte insondável busca ser atravessada pelo conhecimento - médico, científico, mas sobretudo administrativo - das personagens em questão. Poética entre a morte e a vida, mais do que poética da morte, a existência funcionalista, representada como absurda, abre-se para o tratamento literário da morte. A narrativa de ficção é uma possibilidade quando, por exemplo, o silogismo de Kiesewietz e o malsucedido preenchimento artificial do escritório em casa não dão conta de responder à experiência única da morte a cada personagem - experiência comum e comunitária a todos os homens: uma possibilidade protagonizada por Ivan Ilitch e Bougran, na ficção, bem como para o leitor.

\section{Referências}

BARRAUD, Boris. La taxinomie des fonctionnaires: entre l'art et l'obsession.

Revue française de droit administratif, Dalloz, p. 269-275, 2014.

BERTHIER, Philippe. La débâcle du genre", in Huysmans à côté et au-delà, Leuven-Paris, Peeters-Vrin, 2001.

BONNET, Gilles. HUYSROMANS. Poétique du seuil. In: BONNET, Gilles; SEILLAN, Jean-Marie (ed.). Huysmans et les genres littéraires. Rennes: Presses Universitaires de Rennes, 2010. p. 103-115.

BORIE, Jean. Huysmans: le diable, le célibataire et Dieu (Préface). Paris: Grasset et Fasquelle, 1991.

BOURETZ, P.; PISIER, E. Le Paradoxe du fonctionnaire. Calmann-Lévy, 1988.

DE QUINCEY, Thomas. Suspiria de Profundis, in The Confessions of an English Opium-Eater and other writings. New York: Oxford University Press, 2008. https://doi.org/10.1093/ oseo/instance.00252665 
DEVOS, Denise; BOUTEILLER, Paul. J.K. Huysmans, fonctionnaire au Ministère de I'Intérieur de 1866 à 1898. Bulletin de la Société J.K. Huysmans, n. 88, 1995.

FREUD, Sigmund. "Vergänglichkeit" [1916 (1915)]. In: BILDENDE KUNST und Literatur, vol. X, Frankfurt a.M., S. Fischer Verlag, 1969.

FREUD, Sigmund. Obras completas, vol. XIV, Rio de Janeiro, Ed. Imago, 1996. Disponível em: http://www.freudiana.com.br/destaques-home/ sobre-transitoriedade.html. Acesso em: $15 \mathrm{dez.}$ 2018.

GERBOD, Paul. Le fonctionnaire dans la littérature du XIXe au XXe siècle, Revue Administrative, 1999.

HUYSMANS, Joris-Karl. Soixante-huit lettres inédites à Gabriel Thyébaut [inédito, consultável sob demanda à Bibliothèque Nationale de France], Lettre XXIV, 16 décembre 1887.

HUYSMANS, Joris-Karl. La Retraite de Monsieur Bougran, Paris, Jean-Jacques Pauvert, 1964.

MELVILLE, Herman. Bartleby, o escrevente. Trad. Bruno Gambarotto. São Paulo: Grua, 2014.

MORGAN, Owen. Deux lettres inédites de J.-K. Huysmans à Léon Hennique. Bulletin J.-K. Huysmans, n. 72, 1981.

SCARDOELLI, Marina Donato. A aposentadoria de Senhor Bougran, in [n.t.]: Revista Literária em Tradução, Florianópolis, n. 14, v. 1, p.102-134, set. 2017. (https://www.notadotradutor. com/previas/(n.t.)_Joris_Karl_Huysmans.html)

TOLSTOI, Lev. A morte de Ivan Ilitch, trad., posfácio e notas de SCHNAIDERMAN, Boris. São Paulo: Ed. 34, 2009. (Coleção "Leste").

VAREILLE, Arnaud. Les rituels de M. Bougran. In: J.-K. Huysmans: littérature et religion. Rennes: Presses Universitaires de Rennes, 2009. p. 139-154. (Coll. "Interférences") https://doi. org/10.4000/books.pur.38962

\section{Autor:}

REGIS MIKAIL ABUd FILHO

Bacharelado em Letras (Francês/Português) na Universidade de São Paulo (FFLCH/FEUSP - 2005/2006). Mestrado em

Literatura geral e comparada (Allgemeine und Vergleichende Literaturwissenschaft) pela Freie Universität Berlin (2011).

Doutoramento em Literatura francesa (2017) pela Université Paris-Sorbonne (Paris-IV).

Orcid: http://orcid.org/0000-0002-5806-0976

E-mail: regismikail@gmail.com 